\title{
Temporal salt stress-induced transcriptome alterations and regulatory mechanisms revealed by PacBio long-reads RNA sequencing in Gossypium hirsutum
}

Delong Wang ${ }^{1,2}$, Xuke Lu², Xiugui Chen², Shuai Wang ${ }^{2}$, Junjuan Wang ${ }^{2}$, Lixue Guo ${ }^{2}$, Zujun Yin², Quanjia Chen ${ }^{1}$ and Wuwei $Y e^{2^{*}}$

\begin{abstract}
Background: Cotton (Gossypium hirsutum) is considered a fairly salt tolerant crop however, salinity can still cause significant economic losses by affecting the yield and deteriorating the fiber quality. We studied a salt-tolerant upland cotton cultivar under temporal salt stress to unfold the salt tolerance molecular mechanisms. Biochemical response to salt stress (400 mM) was measured at $0 \mathrm{~h}, 3 \mathrm{~h}, 12 \mathrm{~h}, 24 \mathrm{~h}$ and $48 \mathrm{~h}$ post stress intervals and singlemolecule long-read sequencing technology from Pacific Biosciences (PacBio) combined with the unique molecular identifiers approach was used to identify differentially expressed genes (DEG).

Results: Antioxidant enzymes including, catalase (CAT), peroxidase (POD), superoxide dismutase (SOD) were found significantly induced under temporal salt stress, suggesting that reactive oxygen species scavenging antioxidant machinery is an essential component of salt tolerance mechanism in cotton. We identified a wealth of novel transcripts based on the PacBio long reads sequencing approach. Prolonged salt stress duration induces high number of DEGs. Significant numbers of DEGs were found under key terms related to stress pathways such as "response to oxidative stress", "response to salt stress", "response to water deprivation", "cation transport", "metal ion transport", "superoxide dismutase", and "reductase". Key DEGs related to hormone (abscisic acid, ethylene and jasmonic acid) biosynthesis, ion homeostasis (CBL-interacting serine/threonine-protein kinase genes, calcium-binding proteins, potassium transporter genes, potassium channel genes, sodium/hydrogen exchanger or antiporter genes), antioxidant activity (POD, SOD, CAT, glutathione reductase), transcription factors (myeloblastosis, WRKY, Apetala 2) and cell wall modification were found highly active in response to salt stress in cotton. Expression fold change of these DEGs showed both positive and negative responses, highlighting the complex nature of salt stress tolerance mechanisms in cotton.
\end{abstract}

Conclusion: Collectively, this study provides a good insight into the regulatory mechanism under salt stress in cotton and lays the foundation for further improvement of salt stress tolerance.

Keywords: Differentially expressed genes, Upland cotton, Abiotic stress tolerance, Crop improvement, PacBio

\footnotetext{
* Correspondence: yew158@163.com

${ }^{2}$ State Key Laboratory of Cotton Biology/Key Laboratory for Cotton Genetic

Improvement, Ministry of Agriculture/Institute of Cotton Research of Chinese

Academy of Agricultural Science, Anyang 455000, Henan, China

Full list of author information is available at the end of the article
}

(c) The Author(s). 2020 Open Access This article is licensed under a Creative Commons Attribution 4.0 International License, which permits use, sharing, adaptation, distribution and reproduction in any medium or format, as long as you give appropriate credit to the original author(s) and the source, provide a link to the Creative Commons licence, and indicate if changes were made. The images or other third party material in this article are included in the article's Creative Commons licence, unless indicated otherwise in a credit line to the material. If material is not included in the article's Creative Commons licence and your intended use is not permitted by statutory regulation or exceeds the permitted use, you will need to obtain permission directly from the copyright holder. To view a copy of this licence, visit http://creativecommons.org/licenses/by/4.0/. The Creative Commons Public Domain Dedication waiver (http://creativecommons.org/publicdomain/zero/1.0/) applies to the data made available in this article, unless otherwise stated in a credit line to the data. 


\section{Background}

Salinity is one of the most limiting factors for plant productivity. Over 800 million hectares, equivalent to $6.5 \%$ of the world's total land area, are currently estimated to be impacted by salinity [1]. Salt stress disturbs ion balance and osmotic homeostasis, leading to metabolic dysfunction and reduction in photosynthetic activity, finally resulting in reduction of crop productivity [2]. Plant salt stress response mechanism is mainly stimulated by osmotic stress and $\mathrm{Na}^{+}$ [3]. Plants employ various mechanisms to deal with salt stress; these mechanisms include minimization of the amount of salt taken up by roots and its partitioning at tissue and cellular levels to avoid buildup of toxic concentrations in the cytosol of functional leaves [4].

Plant's physiological responses to salt stress involve a number of pathways, including hormone signaling transduction pathway, salt over sensitive pathway (SOS) and hormone biosynthesis pathways [5-9]. Phytohormones such as abscisic acid (ABA), ethylene (ET) and jasmonates (JA) play major roles against abiotic stresses. Abiotic stresses especially cold, heat and salinity are well known for inducing production of these hormones in plant under stress $[6,10,11]$. Salt stress also induces burst of oxidative stress by increasing production of reactive oxygen species (ROS). High ROS level causes molecular damage to DNA, proteins and lipids and also causes cell death in severe conditions [12-14]. Plants have developed antioxidant response mechanisms to scavenge this oxidative stress. Superoxide dismutase (SOD), peroxidase (POD) and catalase (CAT) are the main enzymatic components of this mechanism [15]. Molecular mechanisms of plant stress tolerance are much more complex than physiological and biochemical processes. Much efforts have been devoted to reveal the molecular mechanisms of plant salt tolerance, with the ultimate goal of improving salt tolerance of crop plants [16].

Although cotton (Gossypium hirsutum) is considered a relatively salt tolerant species, salinity can still have significant negative effects on its growth and productivity [17]. Cotton's productivity and fiber quality are adversely affected by high salinity [18]. Salinity affects primary and secondary root development $[19,20]$, and limits photosynthesis and respiration, flowering, boll and fiber quality, and ion uptake in cotton, resulting in significant yield losses [21]. Expression levels of genes related to many biological processes and pathways are significantly affected by salt stress [22, 23]. The identification of salt tolerance genes is of key importance for improving cotton yield in salt affected lands $[24,25]$. Limited number of salt tolerance genes have been identified in cotton as compared to other model plants $[26,27]$.

Genome-wide identification of salt stress related genes and regulatory pathways have been possible due to recent advances in high-throughput sequencing [7-9, 28-30]. Recently, a transcriptome study has revealed the molecular regulatory pathways to salt stress tolerance in cotton based on mRNA and miRNA networks in two contrasting cotton genotypes [16]. Unfortunately, we are still far behind in getting the complete understanding of salt stress tolerance and regulatory mechanisms, especially because of the limited time points investigated during salinity stress applications. Here, we investigated an upland cotton genotype under temporal salt stress. We compared all differentially expressed genes at four time-points with control to explore the plant's response to salt stress under different time intervals. The results provided good insights into the regulatory pathways involved in response to salt stress in cotton.

\section{Results}

\section{Biochemical response to salt stress in cotton}

The cotton cultivar Zhong9807 which is a high salttolerant genotype [23, 31] was used in this study and subjected to different salt stress time durations $(0 \mathrm{~h}, 3 \mathrm{~h}$, $12 \mathrm{~h}, 24 \mathrm{~h}$ and $48 \mathrm{~h}$ ). Under salt stress, excessive accumulation of reactive oxygen species (ROS) creates oxidative stress and in response, plants induce antioxidant response mechanisms by activating superoxide dismutase (SOD), peroxidase (POD), catalase (CAT) enzymes to scavenge ROS [15]. In this study, SOD, CAT, and POD were measured on young leaves collected at each time point under salt stress. CAT and POD showed continuous and significantly increased activity under temporal stress, while SOD activity showed a slight decrease after $12 \mathrm{~h}$ of stress (Fig. 1). However, SOD activity was significantly higher under salt stress conditions $(3 \mathrm{~h}, 12 \mathrm{~h}, 24 \mathrm{~h}$ and $48 \mathrm{~h})$ when compared to the control condition $(0 \mathrm{~h})$ $(P<0.05)$. Malondialdehyde (MDA) content is associated with lipid peroxidation via an increased generation of ROS [32]. Hence, a high level of MDA is an indicator of a high level of stress damage. Here, we found that the level of MDA increased until $12 \mathrm{~h}$ under salt stress, indicating that the plants experienced salt stress damage. However, after $12 \mathrm{~h}$ MDA level decreased sharply to reach a normal state as compared to the control condition $(P=0.19)$. This suggests that the sharp induction of antioxidant enzymes helped to scavenge ROS and led to cellular homeostasis. Therefore, we propose that ROSscavenging antioxidant machinery is an essential component of salt tolerance mechanism in cotton.

\section{Processing and mapping of RNA-seq data}

Fifteen sequencing libraries were constructed from five time points including, control $(0 \mathrm{~h})$ and four temporal salt stress treatments $(3 \mathrm{~h}, 12 \mathrm{~h}, 24 \mathrm{~h}$ and $48 \mathrm{~h}$ ) and used for single-molecule long-read sequencing on the Pacific Biosciences (PacBio) platform. .

A total of $174 \mathrm{~Gb}$ of data were generated with over a million of polymerase reads (Table S1). The adaptors and low-quality sequences were filtered out, resulting in 

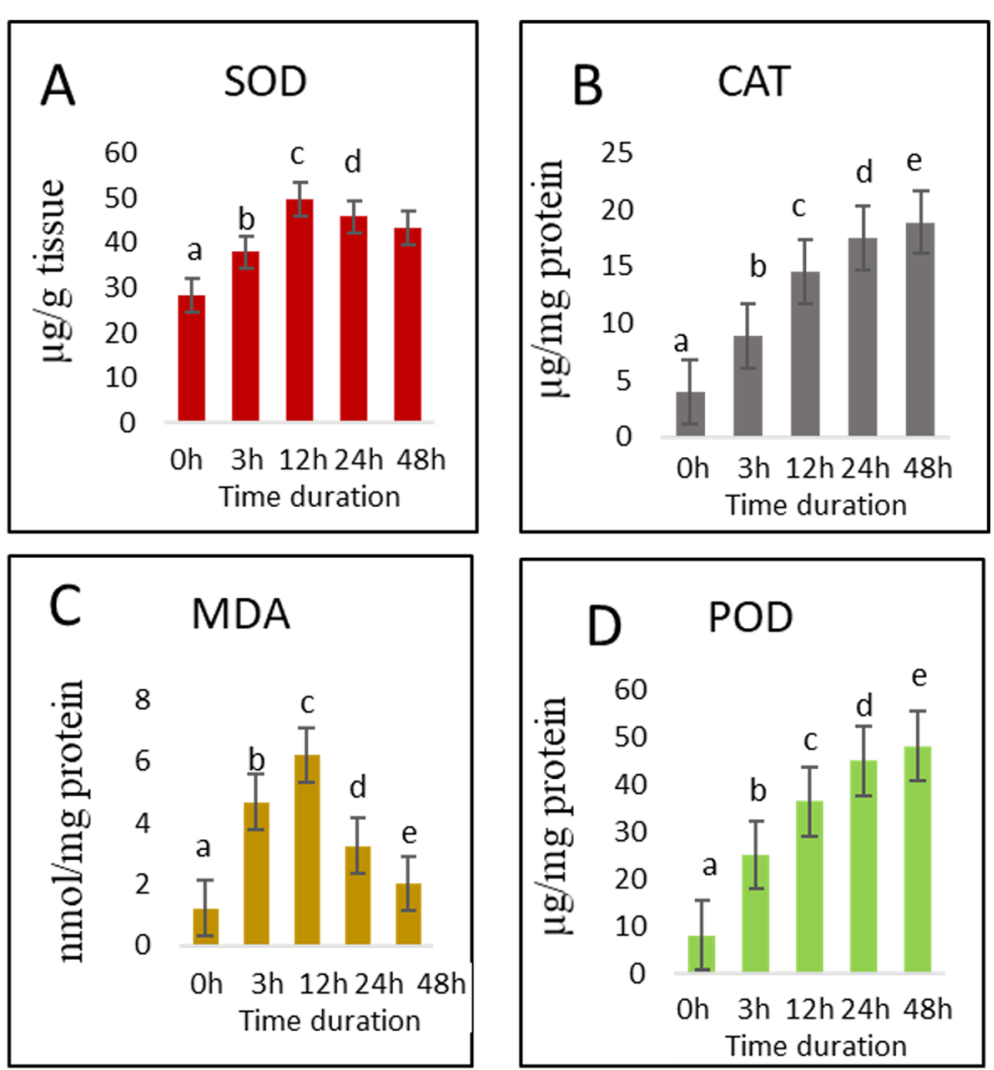

Fig. 1 Biochemical and enzymatic activity under salt stress in cotton for (A) superoxide dismutase (SOD), (B) catalase (CAT), (C) malondialdehyde (MDA) and (D) peroxidase (POD). Data were measured at different time points under salt (400 mM) treatments. Letters above the bar (a, b, c) show the pair comparison. The bars sharing same letters represent groups which are statistically homogeneous. Error bars represent standard error

a total of 98 million subreads. High quality reads of insert (ROIs) were further generated (8.6 million) after filtering CCS with full passes and accuracy. ROIs were classified as full length (FL) transcripts based on the presence of $5^{\prime}$ primers, $3^{\prime}$ primers and poly(A) tails. After polishing, clustering and demultiplexing of FL transcripts, on average we obtained 192,000 non-redundant high-quality FL nonchimeric (FLNC) transcripts with a mean length of 2400 bp in each library (Table S1). Isoforms were mapped to the reference genome and $98.55-98.87 \%$ of them were successfully mapped, whereas $1.25-1.45 \%$ isoforms were unmapped in each sample. Unique mapped isoforms ranged from $90.63-90.21 \%$, while $68.64-74.96 \%$ of the isoforms were perfectly mapped (without any structural variation) to the reference genome (Table 1).

\section{Overview of the alternative splicing events and effect of salt stress treatments}

A major advantage of PacBio sequencing is the possibility of identifying alternative splicing (AS) events by comparing isoforms of the same gene without de novo assembly. In this study, a total of 4,361,815 transcripts were classified into known transcripts, AS, novel and others. Known transcripts accounted only for $9.9 \%$ of the total transcripts while alternative spliced and novel transcripts accounted for 69.4 and $16.2 \%$, respectively

Table 1 Statistics of isoform mapping to the reference genome

\begin{tabular}{lllllll}
\hline Time points & Input & Mapped (\%) & Unmapped (\%) & Perfect mapped (\%) & Unique mapped (\%) & Multiple mapped (\%) \\
\hline O h & 380,361 & 98.6 & 1.4 & 68.64 & 90.63 & 7.97 \\
$3 \mathrm{~h}$ & 400,895 & 98.85 & 1.15 & 70.94 & 91.2 & 7.65 \\
$12 \mathrm{~h}$ & 377,903 & 98.67 & 1.33 & 71.53 & 91.17 & 7.49 \\
$24 \mathrm{~h}$ & 350,330 & 98.55 & 1.45 & 68.06 & 91.21 & 7.34 \\
$48 \mathrm{~h}$ & 383,056 & 98.75 & 1.25 & 74.96 & 91.19 & 7.56 \\
\hline
\end{tabular}


(Fig. 2a). This result highlights the importance of AS in cotton transcriptome particularly under salt stress treatment. The isoforms were classified into five AS types, including intron retention (IR), alternative exon (AE), exon skipping (SKIP), alternative transcript start and termination (TSS, TTS). As shown in Fig. 2b, IR and AE were the most abundant AS types in our experimental conditions. The number of AS types ranges from 2 to 436 with the gene GH_D02G2617 having the highest number of isoforms (Table S2).

We further investigated the effect of salt stress treatments on AS profiles in cotton FL transcriptome. The number of AS events steadily increased from $0 \mathrm{~h}$ to $12 \mathrm{~h}$ under salt stress then, subsequently dropped until $48 \mathrm{~h}$ (Fig. 2c). This pattern is similar to the observed antioxidant enzyme activities under salt stress (Fig. 1). In more details, we observed that salt treatments not only affected AS number but also deeply influenced the AS types (Fig. 2c).

\section{Gene expression analysis at each time point}

Quantitative RNA-seq analysis was performed based on the unique molecular identifiers (UMI) approach described by Islam et al. [33]. Fragments Per Kilobase of transcript sequence per Millions of base pairs sequenced (FPKM) values were used to calculate the transcript abundance. The highest number of transcripts was expressed in control $(0 \mathrm{~h})$ sample while the lowest number of transcripts was expressed under $48 \mathrm{~h}$ salt stress sample (Fig. 3a), indicating that salt treatments globally reduce gene transcription in cotton. We constructed a venn diagram to show common and unique transcripts expressed among all samples. A total of 20,088 genes were commonly expressed among all samples and only few genes were time-specific (Fig. 3b).
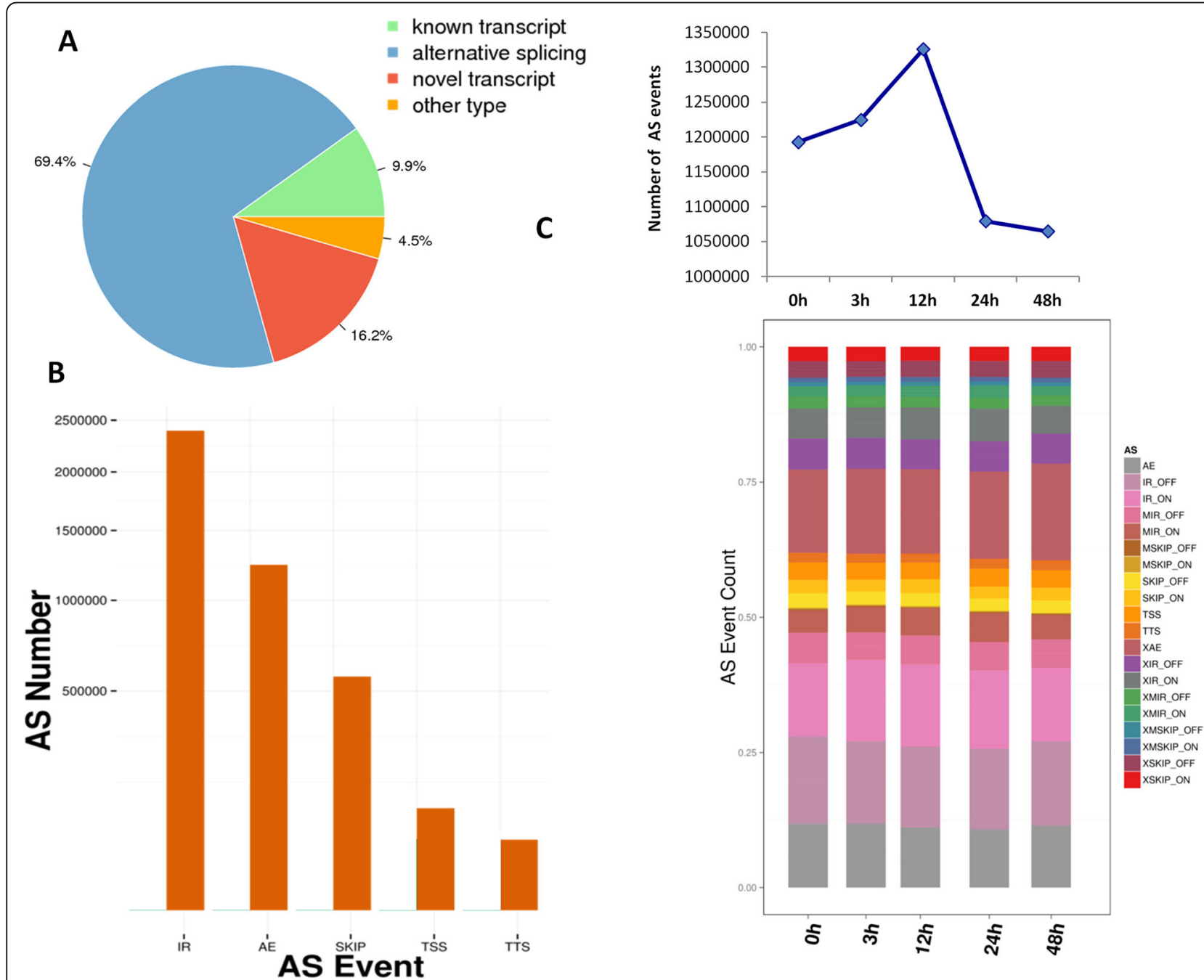

Fig. 2 Classification of the isoforms and analysis of the alternative splicing events. a Classification of transcripts; $\mathbf{b}$ Distribution of the isoforms into five AS types; c Variation of the number of AS event over a temporal salt stress time treatment. Gene number according to the expression level (FPKM) at each time point. 0, 3, 12, 24 and $48 \mathrm{~h}$ represent the different time points of salt stress ( $400 \mathrm{mM})$ duration 

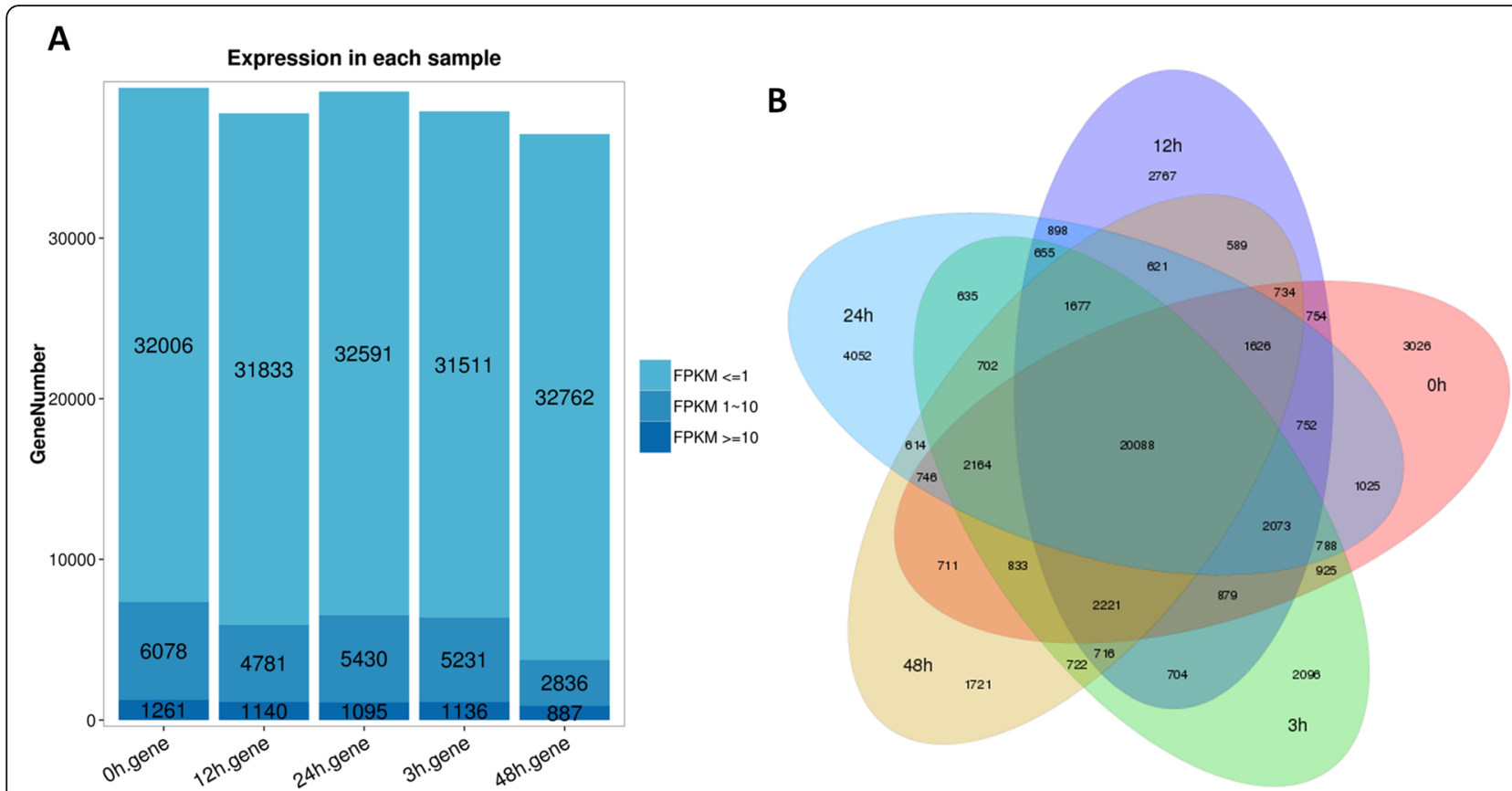

Fig. 3 Gene expression profiles. a Gene number according to the expression level (FPKM) at each time point; b Venn diagram showing common and unique expressed genes at each time point. 0, 3, 12, 24 and $48 \mathrm{~h}$ represent the different time points of salt stress (400 mM) duration

Estimation of DEGs was done by using cut off $P$ value of 0.05 adjusted by Benjamini and Hochberg's approach and fold change $\geq 2$. Results showed that the numbers of DEGs increased with prolonging salt stress duration (Table 2). We first tested the reliability of the DEG detection through a qRT-PCR gene expression profiling of 20 randomly selected DEGs. A high correlation between the qRT-PCR results and the transcriptome results $\left(R^{2}=0.79\right)$ showed that our DEG analysis were highly reliable (Table S3, Figure S1).

Then, we performed gene ontology (GO) and Kyoto Encyclopedia of Genes and Genomes (KEGG) pathway enrichment analyses to understand the functions of the DEGs. For GO terms, we annotated 5498 (65.11\%), 5907 (65.85\%), 5899 (60.56), 7529 (68.83\%) DEGs for $0 \mathrm{~h}-\mathrm{vs}-3 \mathrm{~h}, 0 \mathrm{~h}$-vs-12 $\mathrm{h}, 0 \mathrm{~h}-\mathrm{vs}-24 \mathrm{~h}$ and $0 \mathrm{~h}-\mathrm{vs}-48 \mathrm{~h}$, comparisons, respectively (Table 3). Down-regulated DEGs outnumbered the upregulated DEGs in each GO category. We compared the DEGs under molecular function category between $0 \mathrm{~h}$-vs-3 $\mathrm{h}$ and $0 \mathrm{~h}-\mathrm{vs}-48 \mathrm{~h}$. The numbers of genes showing differential expression in each GO term were higher under $0 \mathrm{~h}$-vs-

Table 2 Numbers of differentially expressed genes between compared time points

\begin{tabular}{llll}
\hline Time points & Total DEGs & up & down \\
\hline 0 h-vs-3 h & 8444 & 3362 & 5082 \\
3 h-vs-12 h & 8673 & 3962 & 4711 \\
12 h-vs-24h & 9541 & 5569 & 3972 \\
24 h-vs-48 h & 10,539 & 1880 & 8659 \\
\hline
\end{tabular}

$48 \mathrm{~h}$ than $0 \mathrm{~h}-\mathrm{vs}-3 \mathrm{~h}$. Three stress related GO terms (catalytic activity, transporter activity and antioxidant activity) were more enriched under $0 \mathrm{~h}$-vs- $48 \mathrm{~h}$ than $0 \mathrm{~h}$-vs- $3 \mathrm{~h}$ (Table S4). It shows that prolonged salt stress duration induces more genes for adjustment in the stressful environment compared to the non-stress condition.

For further investigations of DEGs related to salt stress, we searched some key pathways related to stress. Significant numbers of DEGs were found under key terms such as "response to oxidative stress", "response to salt stress", "response to water deprivation", "cation transport", "metal ion transport", "superoxide dismutase", and "reductase" (Table 4). Based on the KEGG enrichment analysis, we observed that hormone synthesis, ROS related and hormone signal transduction related pathways were significantly enriched (Fig. 4; Table S5).

\section{DEGs involved in hormone biosynthesis}

Plant hormones play a crucial role in stress tolerance mechanism [6,34]. Plant's response to stress mainly depend on stress hormones for signal transduction [12]. Abscisic acid

Table 3 Gene ontology annotation of differentially expressed genes

\begin{tabular}{lllll}
\hline Time points & up & down & total & $\%$ annotated \\
\hline 0 h-vs-3 h & 2173 & 3325 & 5498 & 65.11 \\
3 h-vs-12 h & 2498 & 3266 & 5764 & 66.46 \\
12 h-vs-24 h & 3157 & 2560 & 5717 & 59.92 \\
24 h-vs-48 h & 1290 & 5007 & 6297 & 59.75 \\
\hline
\end{tabular}


Table 4 Numbers of differentially expressed genes in each gene ontology (GO) term related to stress

\begin{tabular}{|c|c|c|c|c|}
\hline GO term & $0 \mathrm{~h}-\mathrm{vs}-3 \mathrm{~h}$ & $0 \mathrm{~h}-\mathrm{vs}-12 \mathrm{~h}$ & $0 \mathrm{~h}-v s-24 \mathrm{~h}$ & $0 \mathrm{~h}-\mathrm{vs}-48 \mathrm{~h}$ \\
\hline Response to oxidative stress & 18 & 16 & 10 & 16 \\
\hline Response to salt stress & 8 & 11 & 9 & 7 \\
\hline Response to water deprivation & 3 & 5 & 3 & 2 \\
\hline Cation transport & 8 & 10 & 10 & 14 \\
\hline Metal ion transport & 9 & 10 & 11 & 14 \\
\hline Superoxide dismutase & 6 & 8 & 8 & 10 \\
\hline Reductase & 34 & 26 & 31 & 33 \\
\hline
\end{tabular}

(ABA), ethylene (ET) and jasmonic acid (JA) are among the most important plant hormones known for long distance signal transduction during stress [11]. We examined KEGG pathways related to biosynthesis of these hormones. Two abscisic acid biosynthesis protein $2(A B A 2)$, three abscisic acid 8'-hydroxylase 1 (ABAH1), two beta-carotene hydroxylase $(B C H)$, four 9-cis-epoxycarotenoid dioxygenase $(N C E D)$ and four phytoene synthase (PSY) genes showed differential expression in ABA biosynthesis pathway (Table S4, Fig. 5). NCED genes have been demonstrated to play an important role in the biosynthetic pathway of ABA [28]. Four NCED genes showed continuous up-regulation during

\section{Hormone and ROS related pathways under salt stress}

Plant hormone signal transduction

Biosynthesis of amino acids

Plant-pathogen interaction

Carbon metabolism

Starch and sucrose metabolism

Protein processing in endoplasmic reticulum

Amino sugar and nucleotide sugar metabolism

Phenylpropanoid biosynthesis

Pentose and glucuronate interconversions

Peroxisome

Cysteine and methionine metabolism

Oxidative phosphorylation

Ascorbate and aldarate metabolism

Glutathione metabolism

Diterpenoid biosynthesis

alpha-Linolenic acid metabolism

Carotenoid biosynthesis

Arginine and proline metabolism

Phenylalanine metabolism

Tryptophan metabolism

Brassinosteroid biosynthesis

Zeatin biosynthesis
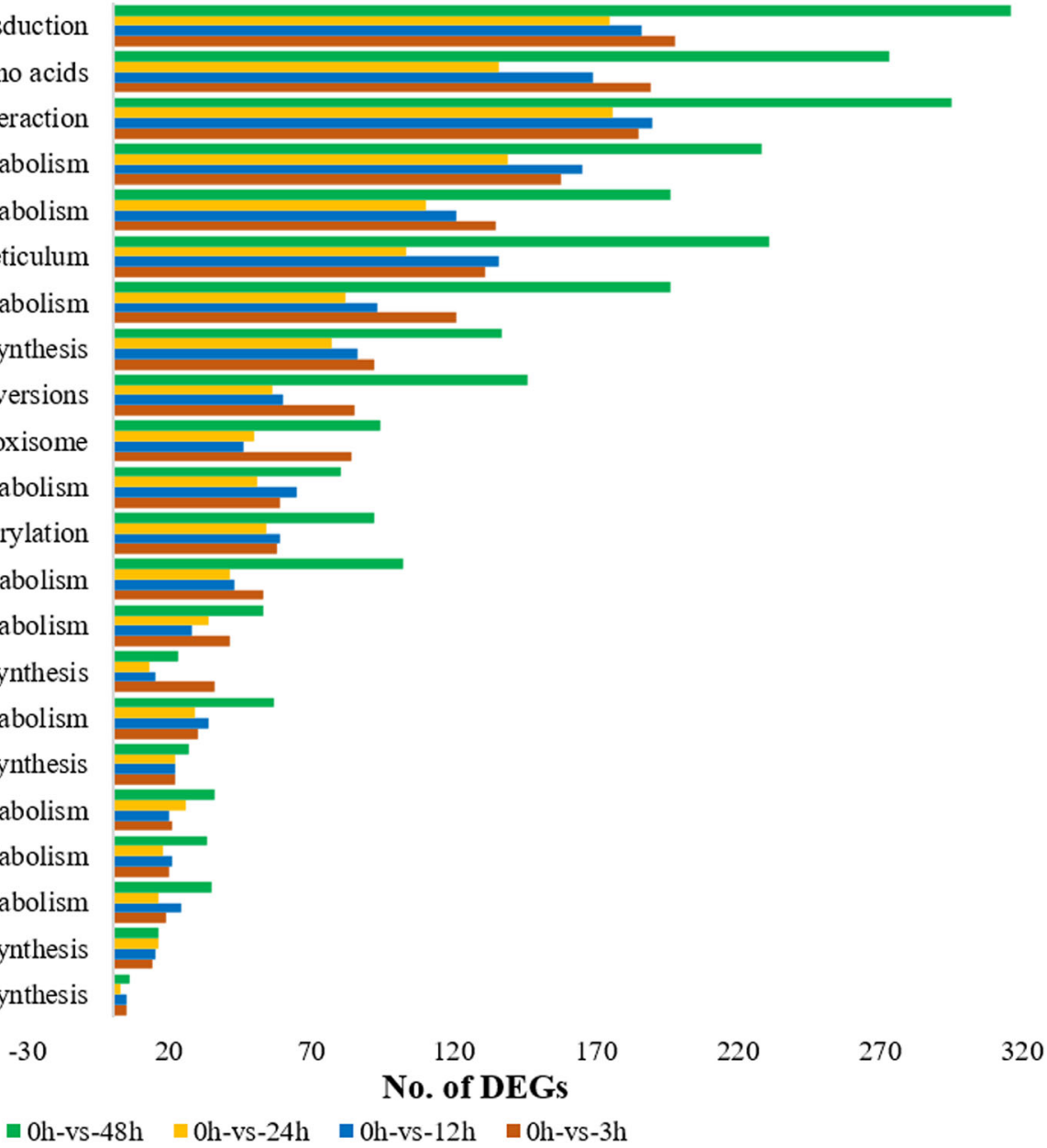

Fig. 4 Hormones and ROS-related pathways under salt stress. 0, 3, 12, 24 and $48 \mathrm{~h}$ represent the different time points of salt stress (400 mM) duration 

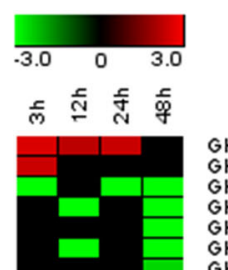

GH_A11G2946 NHX1GH_D11G2977 NHX1 GH_A12G0075 NHX2 GH_D09G0747 NHX2 GH_D11G2682 NHX2 $\mathrm{GH}_{-} \mathrm{D12G0079} \quad \mathrm{NHX2}$ $\mathrm{GH}_{-}^{-} \mathrm{A0}_{2} \mathrm{G0482} \quad \mathrm{NHX3}$ $\mathrm{GH}_{-}^{-} \mathrm{A09G0801} \mathrm{NHX3}$ $\mathrm{GH}^{-} \mathrm{D} 13 \mathrm{G} 1142 \mathrm{NHX}$ $\mathrm{GH}^{-} \mathrm{DO6G2121} \mathrm{NHX}$ $\mathrm{GH}^{-} \mathrm{A0} 1 \mathrm{G} 0318 \mathrm{NHX}$ $\mathrm{GH}^{-} \mathrm{A06 \textrm {G } 2 0 8 3} \mathrm{NHXB}$ $\mathrm{GH}_{-}^{-} \mathrm{A03G1323}$ NHX7 $\mathrm{GH}_{-}^{-} \mathrm{A08G} 2082$ CIPK1 GH_DO6G2120 CIPK1 GH_A09G0855 CIPK1 GH_D09G0811 CIPK1 GH_DO2G0049 CIPK2 GH-A09G1230 CIPK3 GH_A02G0995 ClPK3 GH-A07G1295 CIPK3 GH GH_D05G0536 CIPK5 $\begin{array}{ll}\text { GH_D07G0372 } & \text { ClPK5 } \\ \text { GH-A05G0538 } & \text { CIPK6 }\end{array}$ GH_A05G0538 CIPK6 GH_A06G1049 CIPK6 GH_D13G2112 CIPK6 GH-A02G0371 CIPK7 GH-A06G0305 CIPK8 $\mathrm{GH}^{-} \mathrm{A11G} 1048$ CIPK $\mathrm{GH}^{-} \mathrm{A} 12 \mathrm{G} 1547$ CIPK9 GH-D11G1075 CIPK9 $\mathrm{GH}^{-} \mathrm{A03G} 1585$ CIPK9 GH-A11G2975 CIPK9 $\mathrm{GH}_{-}^{-} \mathrm{A05G3075}$ CIPK9 $\mathrm{GH}_{-}^{-} \mathrm{A02} 20843$ CIPK9$\mathrm{GH}_{-}^{-} \mathrm{A07 \textrm {G0024 }}$ AKT1 $\mathrm{GH}_{-}^{-} \mathrm{A} 13 \mathrm{G} 2271$ AKT GH_D07G0032 AKT $G H_{-}^{-D 02 G 2347}$ AKT GH-D11G1243 HAK1 GH-A01G1525 HAK17 GH_D01G1614 HAK17 GH-D10G1035 HAK23 GH_D GH_A10G0415 KAT GH_D10G0437 KAT GH_A03G1077 CML GH_AO4G1762 CML GH_A05G2319 CML GH_A05G2383 CML GH-A05G3872 CML GH-A07 G0434 CML $\mathrm{GH}^{-} \mathrm{A07G0848} \mathrm{CML}$ $\mathrm{GH}^{-} \mathrm{A11G2005} \mathrm{CML}$ $\mathrm{GH}^{-} \mathrm{A} 12 \mathrm{G0674} \mathrm{CML}$ GH_A13G0759 CML GH-D05G2403 CML GH_D06G0159 CML GH_D07G0851 CML GH_D11G1989 CML GH_D11G2045 CML GH_D12G0685 CML GH_D12G2915 CML GH_D12G2915 CML

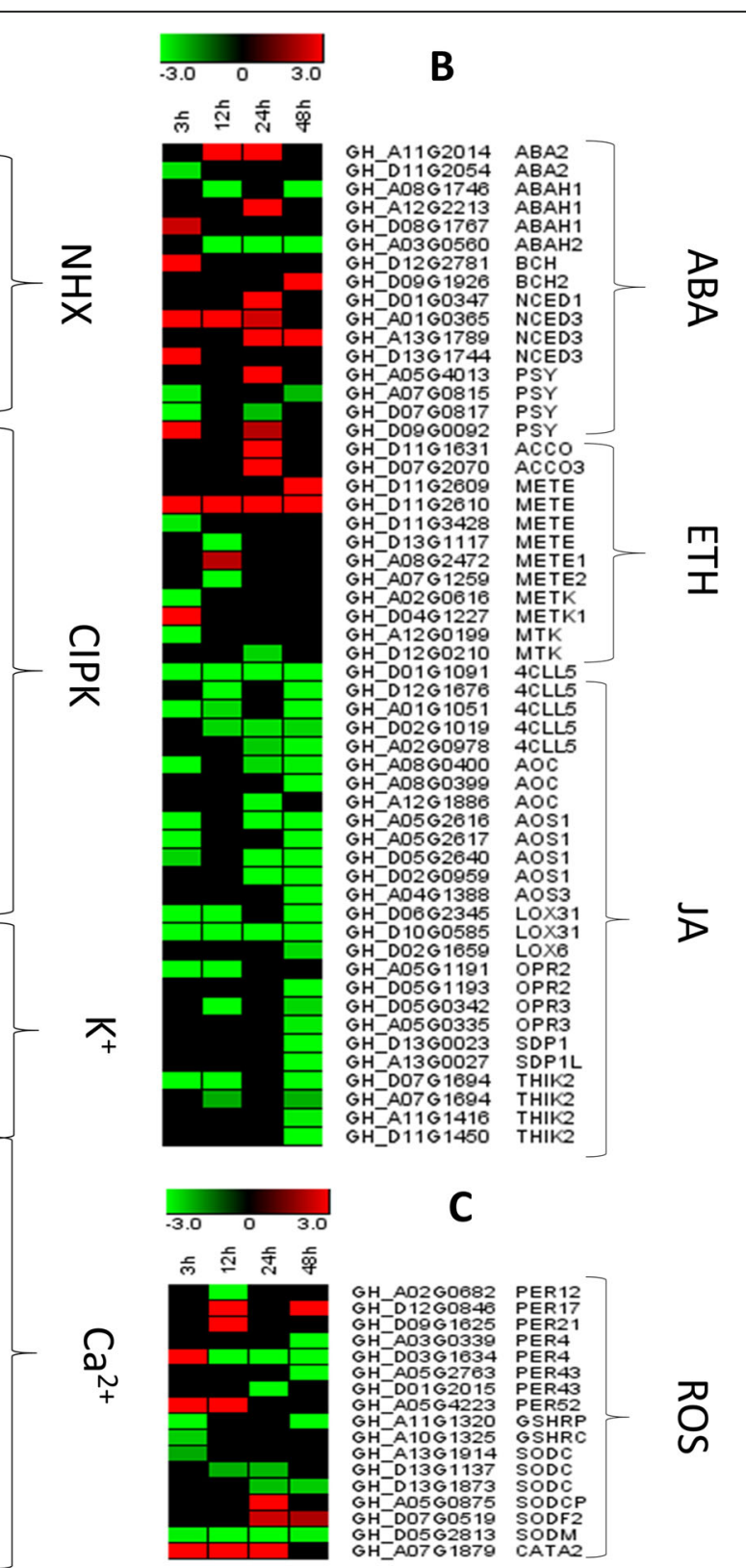

Fig. 5 Expression profiling of ion homeostasis (a), hormone synthesis (b) and ROS related (c) DEGs. 0, 3, 12, 24 and 48 h represent the different time points of salt stress $(400 \mathrm{mM})$ duration

all stress stages. In the JA biosynthesis pathway, 26 genes showed differential expression under salt stress. These genes include five 4-coumarate--CoA ligase-like 5 (4CCL5), three Allene oxide cyclase $(A O C)$, four Allene oxide synthase 1 (AOS1), two Linoleate 13S-lipoxygenase 3-1 (LOX), four 12-oxophytodienoate Reductase 2 (OPR), two Triacylglycerol lipase (SDP1) and four 3-ketoacyl-CoA thiolase 2 (THIK) genes (Table S6, Fig. 5). Most of these genes were down-regulated under salt stress. In the ethylene biosynthesis pathway, 12 differentially expressed genes were found. Most of these genes showed positive regulation with the increase of stress duration. These results indicate that ABA, JA and Ethylene related DEGs play crucial roles for cotton response to salt stress.

\section{DEGs related to antioxidant activity}

Salt stress leads to oxidation stress through overaccumulation of ROS. ROS is known for its negative effect on plant growth, productivity and other biological processes [13]. Plants have developed ROS scavenging mechanisms to avoid oxidative stress. Under stressful conditions, the balance between ROS production and 
scavenging is disturbed leading to over-accumulation of ROS, especially $\mathrm{H}_{2} \mathrm{O}_{2}$, in plant tissues [14]. Some antioxidant enzymes such as peroxidase (POD), superoxide dismutase (SOD), catalase (CAT) and glutathione reductase (GR) play an important role in ROS scavenging mechanism $[10,12]$. We found eight genes from the POD family showing differential expression in our data. Four of these genes were up-regulated in salt stress conditions (Table S7, Fig. 5). One catalase gene (GH_A07G1879) was upregulated under salt stress conditions. Six genes from the SOD family showed differential expression (Table S7, Fig. 5), with two up-regulated under salt stress conditions. Finally, we found two genes related to GR, both downregulated under salt stress conditions. Differential expression of antioxidant related genes correlates well with the observed increased activity of antioxidant enzymes under salt stress except for SOD and POD. Some of the SOD and POD related genes were down-regulated with increasing salt stress duration, while POD and SOD enzymes showed continuous increased activities. This suggests that down-regulation of some POD and SOD genes did not affect the enzymatic activities under salt stress (Fig. 1).

\section{Ion homeostasis related DEGs}

Ion balance is greatly damaged after exposure to salt stress [35-44]. High concentration of $\mathrm{Na}^{+}$activates the $\mathrm{Ca}^{2+}$ signaling pathway. The role of $\mathrm{Ca}^{2+}$ as a secondary messenger is well known [15]. We found 25 CBL-interacting serine/ threonine-protein kinase 1 (CIPK) genes showing significant differential expression under salt stress conditions (Table S8, Fig. 5). CIPK genes have been reported for playing a crucial role in salt overly sensitive (SOS) signaling and $\mathrm{Ca}^{+}$signaling pathways [37]. We also found 21 calcium-binding protein (CML) DEGs (Table S6, Fig. 5). $C M L$ genes interact with $S O S$ pathway and CIPK genes to activate the $\mathrm{Ca}^{+}$signaling pathway [38]. Three DEGs encoding potassium transporter $(H A K)$ were detected under salt stress (Table S8, Fig. 5). These genes are reported as potassium transporters [39-42]. Furthermore, we found six potassium channel $(A K T, K A T)$ genes showing differential expression [43]. $A K T$ and $K A T$ are crucial potassium ion homeostasis. Sodium/hydrogen exchanger or antiporter genes $(N H X)$ also play an important role in exclusion of excessive sodium ions under salt stress [44]. We found 14 NHX DEGs with various patterns of regulation under salt stress (Table S8, Fig. 5).

\section{Transcription factors related to salt stress}

Transcription factors (TF) play key roles in gene regulation. Plants use transcription modulation in response to stress conditions [45, 46]. Stress responsive TFs modulate many genes related to ABA biosynthesis and signal transduction. Transcription families such as myeloblastosis $(M Y B), W R K Y$ and ERF have been reported to regulate stress tolerance in plants [47]. In our data, 23 TF families containing 5723 members were detected. We found 26, 26, 18 and 35 TFs showing significant differential expression in $3 \mathrm{~h}, 12 \mathrm{~h}, 24 \mathrm{~h}$ and $48 \mathrm{~h}$ salt stress, respectively, compared to $0 \mathrm{~h}$. Most of these TFs were members of APETALA 2 (AP2), WRKY and MYB families (Table S9).

\section{DEGs related to cell wall modification}

Salinity stress affects plant growth by inhibiting cell elongation and limiting cellulose synthesis. Cell wall becomes rigid and root growth gets affected [48]. Multiple regulatory processes come into action to resume the normal growth of the plant cells. Understanding the molecular mechanisms regulating cell wall integrity and modification could be useful for improving salt stress tolerance in plants. We found 235 DEGs related to cell wall biosynthesis and modification under salt stress (Table S8). Cellulose is one of main components of cell wall [49]. We found 50 DEGs related to cellulose biosynthesis. Most of these genes were down-regulated under slat stress. Only 19 genes were up-regulated (Table S10). We also found 17 DEGs related to cellulose catabolic process and 6 DEGs related to cellulose microfibril organization showing.

After cellulose, lignin is the second most abundant compound in plants. It gives plants the ability to stand. Lignification of plant cell wall is affected under various abiotic stresses [50]. We found seven DEGs related to lignin catabolism under salt stress (Table S10). All of these genes were up-regulated. Expansins play important role in cell elongation by loosening the cell wall [51]. We found 21 expansin genes showing differential expression under salt stress. Only five out of the 21 expansin DEGs were up-regulated. We also found one extensin gene (EXTN) down-regulated under salt stress (Table S10). Pectin is another important component of cell wall structure. Under various abiotic stresses, pectin can stiffen the cell wall and slow down the growth [48]. We found $42 \mathrm{DEGs}$ related to pectin catabolic process under salt stress. Only 12 out of the 42 DEGs were up-regulated (Table S10). Galacturonosyltransferases are important enzymes involved in pectin biosynthesis [48]. We found 28 DEGs related to galacturonosyltransferase activity under salt stress (Table S10). Osmotic stress can induce peroxidases in plants. Peroxidases play role in cross-linking various cell wall structural proteins [52]. We found seven DEGs related to peroxidase activity under salt stress. Two of these genes were significantly up-regulated. Receptor-like kinases have also been proved to play important role in cell wall modification under salt stress [53]. We found seven receptor-like kinase genes showing significant differential expression under salt stress (Table S10). Xyloglucans are hemi cellulosic polymers present in cell wall structure. They play role in cell wall organization [48]. In our experiment, we found 37 genes related to xyloglucan showing differential expression. Thirteen out of the 37 
DEGs were up-regulated. Nine out of ten genes related to cell wall structural proteins were up-regulated under salt stress. One gene encoding for leucine-rich repeat extensin like protein was down-regulated (Table S10).

\section{Discussion}

Salinity stress negatively affects plant growth and other developmental processes. Salinity induces osmotic stress and ionic imbalance leading to ion toxicity and production of reactive oxygen species (ROS) [10]. After receiving the stress stimulus, receptors activate secondary signaling pathways such as $\mathrm{Ca}^{+}$, ROS and hormone signaling [13]. These signal molecules activate salt stress tolerance mechanism related genes. Although cotton is moderately tolerant to salt stress, its salt tolerance mechanism is not well understood [54]. In this study, we applied temporal salt stress to cotton plants and used PacBio long reads combined with the unique molecular identifiers approach [33] to examine differential expression of genes at each time point. We identified a wealth of novel transcripts based on the PacBio long reads sequencing approach, which is accordance with previous report of Wang et al. [55]. We compared four time points of varying stress duration with control. A significant number of DEGs were found under salt stress at each time point. We focused on hormone biosynthesis, ion homeostasis and antioxidant related pathways to further investigate salt tolerance mechanism in cotton.

Phytohormones, especially ABA, play major role of signal transduction under abiotic stress [56]. Increased level of $\mathrm{ABA}$ in plant under salt stress promotes membrane stability and $\mathrm{Ca}^{+}$uptake [34]. In this study, ABA biosynthesis genes ( $A B A, B C H, N C E D, P S Y)$ were activated during early stages of stress and showed continuous upregulation at all time points. Genes related to ABA degradation also showed differential expression. Some of these genes were up-regulated at late stages of stress, which implies that activation of these genes was in response to balance the ABA content in the plant tissues. Regulation of ABA biosynthesis genes under salt stress depicts their crucial role in stress tolerance mechanism. A considerable number of ethylene and JA related genes were also activated at early stress stage and showed continuous differential expression at all time points. Various studies have reported the role of endogenous ethylene production or treatment with ethylene in enhancing salinity tolerance $[57,58]$. Some studies have also reported negative effect of higher level of ethylene on salt tolerance in plants $[59,60]$. These results suggest that ethylene regulates salinity tolerance negatively or positively according to the endogenous concentration and optimising the ethylene production in plants can enhance salt stress tolerance.
Salt stress increases $\mathrm{Na}^{+}$concentration in the cytosol. Plant uses $\mathrm{Na}^{+} / \mathrm{H}^{+}$exchanger (NHX protein) to regulate $\mathrm{Na}^{+}$concentration [61-63]. NHX proteins located in plasma membrane pump out excessive $\mathrm{Na}^{+}$ions from cell, while NHX proteins located in the tonoplast direct the $\mathrm{Na}^{+}$ion into the vacuole and maintain ion homeostasis in the cytosol [14]. The SOS signaling pathway has been well documented for playing preponderant role in ion homeostasis [64]. Salt stress changes the free $\mathrm{Ca}^{+}$ concentration in the cytosol. Change in $\mathrm{Ca}^{+}$concentration activates SOS3 and SOS2. SOS3-SOS2 complex brings $\mathrm{Na}^{+} / \mathrm{H}^{+}$exchanger into action and the excess $\mathrm{Na}^{+}$ is excluded from the cytosol [38]. Potassium channels and transporters also play key role in ion homeostasis [65]. In the present study, three sodium/proton antiporters were up-regulated. Potassium transporters and channels (AKT, HAK, KAT) and SOS pathway related genes $(C I P K, C M L)$ showed significant differential expression under salt stress. Regulation of these genes under salt stress is consistent with previous studies [29, 65-69]. Although many studies have proved the role of ion homeostasis related genes in salt stress tolerance, the interaction of these genes to confer the stress tolerance is yet to be explored.

Salt stress also induces bursts of oxidative stress by increasing the production of ROS [70]. High ROS level causes molecular damage to DNA, proteins and lipids, resulting in cell death under severe conditions [12-14]. Plants have developed antioxidant response mechanism to scavenge this oxidative stress. Superoxide dismutase (SOD), peroxidase (POD) and catalase (CAT) are the main enzymatic components of this mechanism [15]. In our study, biochemical analysis of the antioxidant enzymatic activity showed a steep increase of the levels of most of the enzymes under salt stress in cotton, indicating that the cotton genotype triggered the antioxidant machinery (CAT, POD, SOD) to buffer ROS production. Although the MDA content increased during the early salt stress stage, it rapidly decreased to reach the normal range after $12 \mathrm{~h}$. This indicates that the enzymatic ROS scavenging machinery was highly efficient to buffer the salt stress damage in cotton. Similarly, eight genes from the POD family, one CAT gene (GH_A07G1879) and six genes from the SOD family showed differential expression under salt stress based on the RNA-seq data. These results are consistent with previous study in which overexpression of GhSOD1 and GhCAT1 increases salt stress tolerance in cotton plants [71]. Regulation of genes related to antioxidants has already been proved in previous studies to play an important role in salt stress tolerance [72-74]. Together with other signaling pathways, ROS scavenging mechanism confers salt stress tolerance [75].

Transcription factors (TF) are very important elements for salt stress tolerance. Various transcription families 
have been characterised and their role in stress tolerance mechanism has been proved. WRKY transcription factors have been reported to play an important role in salt stress tolerance mechanism [76, 77]. MYB transcription factors have also been reported in rice to modulate gene expression under salinity stress [36]. Our study reports 24 TF families showing differential expression under salt stress. Among these WRKY, MYB, MYB-related, AP2-EREFF and GRAS (GAI, RGA, SCR) TF families had highest number of DEGs. Three members of $b H L H$ family were up-regulated under salt stress. Various members of $b H L H$ family ( $V v b H L H 1$, CgbHLH001, EcbHLH57, and TbHLH39) enhance salt stress tolerance in transgenic plants [78-81]. Future studies on the identification of the major regulators within these TFs using approaches such as gene co-expression analysis will provide crucial tools to further enhance salt tolerance and improve productivity in cotton.

Cell wall in plant provides hardness and strength to stand against gravity and its chemical composition change during the course of growth and development. Cell wall is mainly composed of celluloses, hemicelluloses, pectin, lignin and some structural proteins [48]. Abiotic stresses have a significant effect on the cell wall structure. Cell elongation can be limited under abiotic stress due to stiffening of the cell wall or limited availability of celluloses [52]. Xyloglucan endotransglucosylase/hydrolase $(X T H)$ and expansins play important role in cell wall organisation [51]. Understanding the regulatory mechanisms responsible for cell wall remodelling under salt stress can be valuable for the improvement of salt stress tolerance mechanisms. Our study revealed some key genes related to cell wall remodelling, differentially expressed under salt stress. Most of the genes related to cellulose biosynthesis and catabolic process were down-regulated under salt stress. A significant number of expansins and xyloglucan genes were upregulated under salt stress. These genes are supposed to play important role in resuming the normal growth by loosening the cell wall and promoting elongation.

Based on our findings and previous work of Deinlein et al. [82], we have proposed a hypothetical salt stress tolerance network in cotton (Fig. 6). Salt stress stimulus is received by sensors in plasma membrane. Hormone synthesis is regulated and hormonal signal transduction activates stress tolerance mechanism by activating relevant regulatory genes. ROS production is stimulated with the induction of salt stress. Antioxidant enzymes came into action to start ROS scavenging process. Salt stress also activates $\mathrm{Ca}^{2+}$ signaling. CBL/CIPK interaction activates SOS1 which leads to exclusion of excessive $\mathrm{Na}^{+}$ions. Sodium/proton antiporter also came into action and $N H X$ proteins present in the tonoplast start pumping excessive $\mathrm{Na}^{+}$ion from the cytosol to the vacuole. Although this hypothetical mechanism gives a good understanding of salt stress tolerance mechanism, more in-depth studies are needed to unfold the complex regulatory mechanisms and propose validated genes for salt tolerance improvement in cotton.

\section{Conclusions}

We studied the molecular response of an upland cotton genotype under temporal salt stress based on long reads transcriptome analysis. Our study reports a wealth of novel transcripts and some key genes showing differential expression under salt stress. Hormone biosynthesis pathways were observed to play active role under salt stress. We also found sodium/proton antiporter genes, potassium and calcium channels, and SOS pathway related genes showing differential expression under salt stress. DEGs related to hormone biosynthesis ( $A B A$, NCED, PSY, AOC, SPD1), ion homeostasis (CIPK, CML, $H A K, A K T, N H X)$, antioxidant activity (POD, SOD, CAT, $G R)$, transcription factors $(M Y B, W R K Y, A P 2)$ and cell wall modification were implicated in response to salt stress. Overall, this study provides a good insight into the complex molecular mechanisms of salt stress response in cotton and lays the foundation for further improvement of salt stress tolerance.

\section{Methods}

Seeds of Gossypium hirsutum cv. Zhong 9807, a high salt-tolerant genotype [23, 31], were obtained from the gene bank of the Institute of Cotton Research, Chinese Academy of Agricultural Sciences, China and were grown in a plant growth chamber. The formal identification of the plant material was undertaken by the corresponding author of this article (Professor Wuwei Ye). The plant material has been deposited at the gene bank of the Institute of Cotton Research, Chinese Academy of Agricultural Sciences, under the accession ID: xcy2399. For the plant growth conditions, the day/night temperature was set at $28{ }^{\circ} \mathrm{C} / 25^{\circ} \mathrm{C}$, the relative humidity was kept at $60-80 \%$, and the light intensity was set at $14 \mathrm{~h} / 10 \mathrm{~h}$ light/dark cycle under $450 \mu \mathrm{mol} \mathrm{m}^{-2} \mathrm{~s}^{-1}$. The seeds were sterilized with $3 \%$ sodium hypochlorite for $10 \mathrm{~min}$ and washed three times using sterile water. The seeds were germinated in a bowl containing sterilized sand soaked with $100 \mathrm{~mL}$ of $1 / 4$ Hoagland nutrient solution. Each bowl contains a single seedling and bowls were watered regularly to keep optimum soil moisture. A preliminary experiment was performed with different salt concentrations $(0 \mathrm{mM}, 200 \mathrm{mM}, 250 \mathrm{mM}, 300 \mathrm{mM}$, $350 \mathrm{mM}, 400 \mathrm{mM}$ ) and a treatment time of $3 \mathrm{~h}$ to choose the optimum salt concentration for inducing salt stress in Zhong 9807 (Figure S2). Salt concentration of 400 $\mathrm{mM}$ was finally selected to induce salt stress. It is also important to mention that the seedlings could not survive under concentrations higher than $400 \mathrm{mM}$. When 


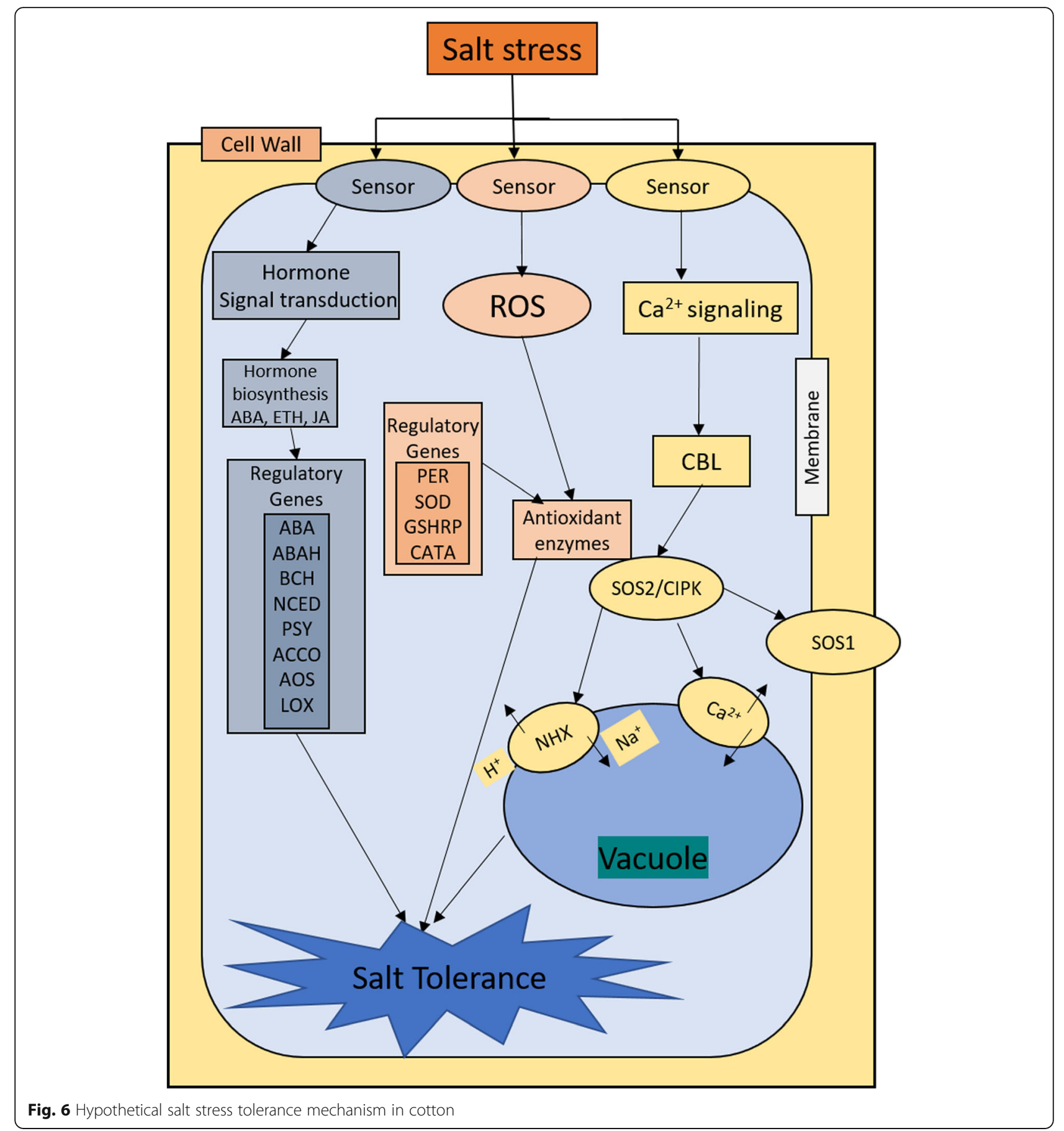

plants grew to 2-3 true leaves stage, $200 \mathrm{~mL}(400$ $\mathrm{mM})$ of salt $(\mathrm{NaCl})$ solution was applied to the bowl. Treatment times were prior salt stress treatment $(0 \mathrm{~h})$, and $3 \mathrm{~h}, 12 \mathrm{~h}, 24 \mathrm{~h}$ and $48 \mathrm{~h}$ post salt stress treatment. Young leaves were harvested in triplicate (three different plants) at every time point, immediately placed in liquid nitrogen and stored at $-80{ }^{\circ} \mathrm{C}$ until use for RNA extraction and to measure the enzymatic activities.

\section{Measurement of enzymatic and biochemical parameters}

Catalase (CAT), Malondialdehyde (MDA), Peroxidase (POD) and Superoxide dismutase (SOD) were measured using Nanjing Jiancheng Bioengineering Institute's relevant kits following manufacturer's instructions and well detailed by Tang et al. [83]. Peroxidase (POD, E.C. 1.11.1.7) activity was assayed by peroxidase assay kit (Catalog No.A084; Jiancheng Bioengineering Institute, Nanjing, China). POD can catalyze the reaction of hydrogen peroxide, the enzyme 
activity of POD was obtained by measuring the change of absorbance at $420 \mathrm{~nm}$. Superoxide dismutase (SOD, E.C. 4 1.15.1.1) activity was measured using a superoxide dismutase activity assay kit (Catalog No. A001-1; Jiancheng Bioengineering Institute, Nanjing, China). SOD activity was determined by the xanthine oxidase method (hydroxylamine). Catalase (CAT, E.C. 1.15.1.1) activity was measured using a CAT activity assay kit (Catalog No. A007-1; Jiancheng Bioengineering Institute, Nanjing, China). CAT can decompose $\mathrm{H}_{2} \mathrm{O}_{2}$ and this reaction can be quickly suspended by adding ammonium molybdate, the rest of $\mathrm{H}_{2} \mathrm{O}_{2}$ combine with ammonium molybdate to produce a paleyellow complex compound, which is detected at $405 \mathrm{~nm}$. Malondialdehyde (MDA) was measured using the $M D A$ assay kit (TBA method) (Catalog No. A003-1; Jiancheng Bioengineering Institute, Nanjing, China) The MDA content was measured at $532 \mathrm{~nm}$ in $\mathrm{nmol} \mathrm{mg} \mathrm{m}^{-1}$ proteins.

\section{Statistical analysis}

Data were analyzed with the R software (www.r-project. org) using the one-way analysis of variance (ANOVA) for significant difference. The error bars were calculated with data from three replicates. ANOVA results were considered significant at $P<0.05$ and mean comparisons were done using the Tukey HSD test.

\section{Library preparation and PacBio sequencing}

Plant leaf tissues at 3-leaves stage were collected for total RNA extraction to construct UMI (unique molecular identifiers) IsoSeq PacBio sequencing libraries following PacBio instructions. Clontech SMARTer PCR cDNA Synthesis Kit and UMI primers were used to synthesize UMI + cDNA. $1+0.4 \mathrm{X}$ AMPure PB beads were used for fragment screening to construct standard full-length transcriptome library. PCR amplification by KAPA HiFi PCR Kits was followed by size selection of PCR product by agarose gel electrophoresis. These cDNA products were purified for library construction using SMRTbell template prep kit 1.0. Libraries were sequenced using $\mathrm{P} 6 \mathrm{C} 4$ polymerase and chemistryon PacBio RS II platform with $240 \mathrm{~min}$ movie time. In this project, we built three UMI IsoSeq PacBio libraries per time point $(0 \mathrm{~h}, 3 \mathrm{~h}$, $12 \mathrm{~h}, 24 \mathrm{~h}$ and $48 \mathrm{~h}$ ). (More about the library construction protocol detail and performance can be found in this wiki: https://github.com/shizhuoxing/BGI-Full-Length-RNA-Analysis-Pipeline/wiki).

\section{Quality control}

Data processing after Pacific Biosciences Sequel was performed with SMRT analysis software suite (http://www. pacb.com/products-and-services/analytical-software/smrtana lysis/) for reads of insert (ROI), Reads classification, Reads clustering and correction (Cluster, Quvier), resulting in high-quality full-length consistent sequences. Briefly, raw polymerase reads were filtered and trimmed to generate the subreads and read of inserts (ROIs) using the RS Subreads protocol, requiring a minimum polymerase read length of $50 \mathrm{bp}$, a minimum polymerase read quality of 0.75 , a minimum subread length of $50 \mathrm{bp}$, and a minimum of one full pass. (Dependencies: SMRTlink v8.0/ ncbi-blast v2.2.26+/ R v3.4.1 with ggplot2 v3.3.0 and gridExtra v2.3.)

\section{Mapping and sequence annotation}

Gossypium hirsutum reference genome [84] and its annotation files were used as background data for the analysis of our transcriptome data. We used GMAP (v2015-09-29) with the parameters "-K 20000 -B 4 -f 2") [85] to align the filtered reads with the reference genome and the result output file was stored in SAM format. Coding sequences (CDS) were identified using Transdecoder [86]. We used the Cuffcompare utility of the Tuxedo suite [87] to categorize each longread transcript with respect to its most closely matching reference transcript. We used Blastn (http://blast.ncbi.nlm.nih. gov/Blast.cgi/v2.2.23) to annotate the Isoforms with NT; Blastx and Diamond (https://github.com/bbuchfink/dia$\mathrm{mond} / \mathrm{v} 0.8 .31$ ) were employed to annotate the Isoforms with NR, KOG, KEGG and SwissProt; Blast2GO (https://www. blast2go.com/v2.5.0) [88] and NR annotation results were used to annotate the Isoforms with GO. The related parameters could be found at this link (https://github.com/shizhuoxing/BGI-Full-Length-RNA-Analysis-Pipeline).

\section{Gene expression quantification and differential expression analysis}

The UMI sequence tagging passed reads was captured according to the positions of the polyA tail and the 3' primer sequence using blast:-outfmt 7-word_size 5 . More details could be found at this link (https://github. com/shizhuoxing/BGI-Full-Length-RNA-Analysis-Pipeline/). Fragments Per Kilobase of transcript sequence per Millions of base pairs sequenced (FPKM) value of each gene was computed based on the UMI-count method described by Islam et al. [33]. In this study, genes with FPKM > 1 were considered expressed.

We used PossionDis ( $\mathrm{R}$ v3.4.1/ Fold Change $>=2.00$ and False Discovery Rate $($ FDR $)<=0.001$ [89]) to screen differentially expressed genes (DEGs) between two samples by referring to the sequencing based differential gene detection method published by Audic et al. [90].

\section{GO and KEGG enrichment analysis of DEGs}

DEGs were also employed for the enrichment analysis of GO using the Blast2GO V2.5.0 [88], which can adjust the gene length bias. The adjusted $P$-value of significantly substantiated GO terms was less than 0.05 . KOBAS V2.0 software was used to detect the KEGG pathways enriched with DEGs [91]. The standard of 
significantly enriched pathway is the same as GO enrichment.

\section{Validation of RNA-seq by qRT-PCR}

Real-time RT-PCR was performed on three replicates of each sample following descriptions of Dossa et al. [92]. Twenty genes were randomly selected for qRT-PCR. NCBI blast was used to design specific primers for the selected genes. Real-time PCR was performed on EDC810 system (Dongsheng innovation Biotechnology Co., Ltd) using SYBR Green Master Mix and results were analyzed by $\Delta \Delta \mathrm{Ct}$ method. Actin gene (F: ATCCTCCGTC TTGACCTTG, R: TGTCCGTCAGGCAACTCAT) was used as control. Each reaction was carried out in a final volume of $20 \mu \mathrm{L}$ containing $10 \mu \mathrm{L}$ of SYBR Green master mix, $0.4 \mu \mathrm{L}$ of each of primer for selected gene and $4 \mu \mathrm{L}$ of cDNA. The PCR thermal cycling conditions were as follows: $95^{\circ} \mathrm{C}$ for $10 \mathrm{~min}$; 40 cycles of $95^{\circ} \mathrm{C}$ for $5 \mathrm{~s}, 60{ }^{\circ} \mathrm{C}$ for $30 \mathrm{~s}$ and $72{ }^{\circ} \mathrm{C}$ for $30 \mathrm{~s}$. Data were collected during the extension step: $95^{\circ} \mathrm{C}$ for $15 \mathrm{~s}, 60^{\circ} \mathrm{C}$ for $1 \mathrm{~min}, 95^{\circ} \mathrm{C}$ for $30 \mathrm{~s}$ and $60^{\circ} \mathrm{C}$ for $15 \mathrm{~s}$.

\section{Supplementary Information}

The online version contains supplementary material available at https://doi. org/10.1186/s12864-020-07260-z.

Additional file 1: Figure S1. qRT-PCR result and correlation analysis with RNA-seq of some selected genes. The cotton Actin gene was used as endogenous gene for normalisation. The error bar represents the SD of three biological replicates.

Additional file 2: Figure S2. Effect of various concentrations of salt $(\mathrm{NaCl})$ on cotton plant (stress time duration was $3 \mathrm{~h}$ ).

Additional file 3: Table S1. Statistics of the PacBio sequencing and data processing

Additional file 4: Table S2. Statistics of the isoforms, corresponding genes and alternative splicing events.

Additional file 5: Table S3. Primer list of transcripts for real-time qRTPCR.

Additional file 6: Table S4. GO enrichment analysis of the differentially expressed genes.

Additional file 7: Table S5. KEGG pathway enrichment of differentially expressed genes.

Additional file 8: Table S6. Differentially expressed genes related to hormone biosynthesis.

Additional file 9: Table S7. Differentially expressed genes related to ROS production and scavenging.

Additional file 10: Table S8. Differentially expressed genes related to ion homeostasis.

Additional file 11: Table S9. Differentially expressed transcription factors under salt stress.

Additional file 12: Table S10. Differentially expressed genes related to cell wall modification under salt stress.

\section{Abbreviations}

PacBio: Pacific Biosciences; DEG: Differentially Expressed Genes; ABA: Abscisic Acid; SOS: Salt Over Sensitive; ROS: Reactive Oxygen Species;

SOD: Superoxide Dismutase; POD: Peroxidase; CAT: Catalase;

MDA: Malondialdehyde; FPKM: Fragments Per Kilobase of transcript sequence per Millions of base pairs sequenced; GO: Gene Ontology; KEGG: Kyoto
Encyclopedia of Genes and Genomes; GR: Glutathione Reductase;

TF: Transcription Factor; ANOVA: Analysis Of Variance

\section{Acknowledgements \\ Not applicable}

Authors' contributions

W.Y. and D.W. conceived and designed the experiments. D.W., X.L., X.C., S.W., J.W. and L.G. conducted the experiment and led the data analysis. X.C., S.W., L.G., Q.C. and Z.Y. contributed to sample preparations, literature search, DNA sequencing and data analysis. D. W. drafted the manuscript. W.Y. provided funding, supervised the study and revised the manuscript. All authors have read and approved the manuscript.

\section{Funding}

This work was supported by funding from the National Key Technology R\&D Program, the Ministry of Science and Technology (2016YFD0100203). The funders had no role in the experimental design, data collection and analysis or writing the manuscript.

\section{Availability of data and materials}

The raw RNA-seq datasets supporting the conclusions of this article are available in the National Center for Biotechnology Information Bioproject repository, accession number: PRJNA559592 (https://www.ncbi.nlm.nih.gov/ bioproject/?term=PRJNA559592). The reference genome of Gossypium hirsutum is available at http://ibi.zju.edu.cn/cotton/.

Ethics approval and consent to participate

Not applicable.

\section{Consent for publication}

Not applicable.

\section{Competing interests}

The authors declare that they have no competing interests.

\section{Author details}

${ }^{1}$ College of Agriculture, Xinjiang Agricultural University, 311 Nongda East Road, Urumqi 830052, P. R. China. ${ }^{2}$ State Key Laboratory of Cotton Biology/ Key Laboratory for Cotton Genetic Improvement, Ministry of Agriculture/ Institute of Cotton Research of Chinese Academy of Agricultural Science, Anyang 455000, Henan, China.

Received: 21 December 2019 Accepted: 19 November 2020 Published online: 27 November 2020

References

1. Rozema J, Flowers T. Crops for a salinized world. Science. 2008;322(5907): 1478-80.

2. Munns R. Genes and salt tolerance: bringing them together. New Phytol. 2005:167(3):645-63.

3. Munns R. Comparative physiology of salt and water stress. Plant Cell Environ. 2002;25(2):239-50.

4. Tang X, Mu X, Shao H, Wang H, Brestic M. Global plant-responding mechanisms to salt stress: physiological and molecular levels and implications in biotechnology. Crit Rev Biotechnol. 2014;35(4):425-37.

5. Parida AK, Das AB. Salt tolerance and salinity effects on plants: a review. Ecotoxicol Environ Saf. 2005:60(3):324-49.

6. Bari R, Jones JD. Role of plant hormones in plant defence responses. Plant Mol Biol. 2009;69(4):473-88.

7. Lai Y, Zhang D, Wang J, Wang J, Ren P, Yao L, Si E, Kong Y, Wang H. Integrative Transcriptomic and proteomic analyses of molecular mechanism responding to salt stress during seed germination in Hulless barley. Int J Mol Sci. 2020;21(1):359.

8. Zhang $X$, Yao Y, Li X, Zhang L, Fan S. Transcriptomic analysis identifies novel genes and pathways for salt stress responses in Suaeda salsa leaves. Sci Rep. 2020;10:4236.

9. Zou C, Liu D, Wu P, Wang Y, Gai Z, Liu L, Yang F, Li C, Guo G. Transcriptome analysis of sugar beet (Beta vulgaris L.) in response to alkaline stress. Plant Mol Biol. 2020;102:645-57. 
10. Julkowska MM, Testerink C. Tuning plant signaling and growth to survive salt. Trends Plant Sci. 2015;20(9):586-94.

11. Nakashima K, Yamaguchi-Shinozaki K. ABA signaling in stress-response and seed development. Plant Cell Rep. 2013;32(7):959-70.

12. Zhu J-K. Salt and drought stress signal transduction in plants. Annu Rev Plant Biol. 2002;53(1):247-73.

13. Baxter A, Mittler R, Suzuki N. ROS as key players in plant stress signalling. J Exp Bot. 2013;65(5):1229-40.

14. Brosché M, Overmyer K, Wrzaczek M, Kangasjärvi J, Kangasjärvi S: Stress signaling III: reactive oxygen species (ROS). In: Abiotic Stress Adaptation in Plants. Netherlands: Springer; 2009. p. 91-102.

15. Foyer $\mathrm{CH}$, Noctor $\mathrm{G}$. Redox homeostasis and antioxidant signaling: a metabolic interface between stress perception and physiological responses. Plant Cell. 2005;17(7):1866-75.

16. Peng Z, He S, Gong W, Sun J, Pan Z, Xu F, Lu Y, Du X. Comprehensive analysis of differentially expressed genes and transcriptional regulation induced by salt stress in two contrasting cotton genotypes. BMC Genomics. 2014;15(1):760.

17. Guozhong Z, Li W, Zhang F, Guo W. RNA-seq analysis reveals alternative splicing under salt stress in cotton, Gossypium davidsonii, vol. 19; 2018.

18. Zhang L, Ma H, Chen T, Pen J, Yu S, Zhao X. Morphological and physiological responses of cotton (Gossypium hirsutum L.) plants to salinity. PLoS One. 2014;9(11):e112807.

19. Leidi E. Genotypic variation of cotton in response to stress by $\mathrm{NaCl}$ or PEG. REUR Technical Series (FAO); 1994.

20. Reinhardt D, Rost T. Primary and lateral root development of dark-and lightgrown cotton seedlings under salinity stress. Bot Acta. 1995;108(5):457-65.

21. Brugnoli $E$, Lauteri M. Effects of salinity on stomatal conductance, photosynthetic capacity, and carbon isotope discrimination of salt-tolerant (Gossypium hirsutum L.) and salt-sensitive (Phaseolus vulgaris L.) C3 nonhalophytes. Plant Physiol. 1991;95(2):628-35.

22. Yao D, Zhang X, Zhao X, Liu C, Wang C, Zhang Z, Zhang C, Wei Q, Wang Q, Yan H, Li F, Su Z. Transcriptome analysis reveals salt-stress-regulated biological processes and key pathways in roots of cotton (Gossypium hirsutum L.). Genomics. 2011;98:47-55.

23. Zhang B, Chen X, Lu X, Shu N, Wang X, Yang X, Wang S, Wang J, Guo L, Wang D, Ye W. Transcriptome analysis of Gossypium hirsutum L. reveals different mechanisms among $\mathrm{NaCl}, \mathrm{NaOH}$ and $\mathrm{Na}_{2} \mathrm{CO}_{3}$ stress tolerance. Sci Rep. 2018:8(1):13527.

24. Jin L-G, Liu J-Y. Molecular cloning, expression profile and promoter analysis of a novel ethylene responsive transcription factor gene GhERF4 from cotton (Gossypium hirstum). Plant Physiol Biochem. 2008;46(1):46-53.

25. Roy SJ, Tucker EJ, Tester M. Genetic analysis of abiotic stress tolerance in crops. Curr Opin Plant Biol. 2011;14(3):232-9.

26. Zhao G, Song Y, Wang Q, Yao D, Li D, Qin W, Ge X, Yang Z, Xu W, Su Z, Zhang X, Li F, Wu J. Gossypium hirsutum Salt Tolerance Is Enhanced by Overexpression of G. arboreum JAZ1. Front Bioeng Biotechnol. 2020;8:157.

27. Zhu G, Gao W, Song X, Sun F, Hou S, Liu N, Huang Y, Zhang D, Ni Z, Chen Q, Guo W. Genome-wide association reveals genetic variation of lint yield components under salty field conditions in cotton (Gossypium hirsutum L.) BMC Plant Biol. 2020;20:23.

28. Xu P, Liu Z, Fan X, Gao J, Zhang X, Zhang X, Shen X. De novo transcriptome sequencing and comparative analysis of differentially expressed genes in Gossypium aridum under salt stress. Gene. 2013;525(1):26-34.

29. Ueda A, Kathiresan A, Bennett J, Takabe T. Comparative transcriptome analyses of barley and rice under salt stress. Theor Appl Genet. 2006;112(7):1286-94.

30. Kawasaki S, Borchert C, Deyholos M, Wang H, Brazille S, Kawai K, Galbraith D, Bohnert HJ. Gene expression profiles during the initial phase of salt stress in rice. Plant Cell. 2001;13(4):889-905.

31. Chen X, Lu X, Shu N, Wang D, Wang S, Wang J, Guo L, Guo X, Fan W, Lin Z, et al. GhSOS1, a plasma membrane $\mathrm{Na}+/ \mathrm{H}+$ antiporter gene from upland cotton, enhances salt tolerance in transgenic Arabidopsis thaliana. PLoS One. 2017;12(7):e0181450.

32. Sheoran S, Thakur V, Narwal S, Turan R, Mamrutha HM, Singh V, Tiwari V, Sharma I. Differential activity and expression profile of antioxidant enzymes and physiological changes in wheat (Triticum aestivum L.) under drought. Appl Biochem Biotechnol. 2015;177(6):1282-98.

33. Islam S, Zeisel A, Joost S. Quantitative single-cell RNA-seq with unique molecular identifiers. Nat Methods. 2013;11(2):163-6.

34. Fahad S, Hussain S, Matloob A, Khan FA, Khaliq A, Saud S, Hassan S, Shan D, Khan F, Ullah N. Phytohormones and plant responses to salinity stress: a review. Plant Growth Regul. 2015;75(2):391-404.
35. Yang Y, Guo Y. Unraveling salt stress signaling in plants. J Integr Plant Biol. 2018:60(9):796-804

36. Zhu J-K. Abiotic stress signaling and responses in plants. Cell. 2016;167(2): 313-24.

37. He L, Yang X, Wang L, Zhu L, Zhou T, Deng J, Zhang X. Molecular cloning and functional characterization of a novel cotton CBL-interacting protein kinase gene (GhCIPK6) reveals its involvement in multiple abiotic stress tolerance in transgenic plants. Biochem Biophys Res Commun. 2013;435(2): 209-15.

38. Sanyal SK, Pandey A, Pandey GK. The CBL-CIPK signaling module in plants: a mechanistic perspective. Physiol Plant. 2015;155(2):89-108.

39. Zhao S, Zhang M-L, Ma T-L, Wang Y. Phosphorylation of ARF2 relieves its repression of transcription of the $\mathrm{K}+$ transporter gene HAK5 in response to low potassium stress. Plant Cell. 2016;28(12):3005-19.

40. Ahmad I, Mian A, Maathuis FJ. Overexpression of the rice AKT1 potassium channel affects potassium nutrition and rice drought tolerance. J Exp Bot. 2016:67(9):2689-98.

41. Chen G, Hu Q, Luo L, Yang T, Zhang S, Hu Y, Yu L, Xu G. Rice potassium transporter O $\mathrm{s}$ HAK 1 is essential for maintaining potassium-mediated growth and functions in salt tolerance over low and high potassium concentration ranges. Plant Cell Environ. 2015;38(12):2747-65.

42. Han M, Wu W, Wu W-H, Wang Y. Potassium transporter KUP7 is involved in $\mathrm{K}+$ acquisition and translocation in Arabidopsis root under K+-limited conditions. Mol Plant. 2016;9(3):437-46.

43. Vanlerberghe GC, Cvetkovska M, Wang J. Is the maintenance of homeostatic mitochondrial signaling during stress a physiological role for alternative oxidase? Physiol Plant. 2009;137(4):392-406.

44. He C, Yan J, Shen G, Fu L, Holaday AS, Auld D, Blumwald E, Zhang H. Expression of an Arabidopsis vacuolar sodium/proton antiporter gene in cotton improves photosynthetic performance under salt conditions and increases fiber yield in the field. Plant Cell Physiol. 2005;46(11):1848-54.

45. Hong $Y$, Zhang H, Huang L, Li D, Song F. Overexpression of a stressresponsive NAC transcription factor gene ONAC022 improves drought and salt tolerance in rice. Front Plant Sci. 2016:7:4

46. Campos JF, Cara B, Pérez-Martín F, Pineda B, Egea I, Flores FB, FernandezGarcia N, Capel J, Moreno V, Angosto T. The tomato mutant ars1 (altered response to salt stress 1 ) identifies an R1-type MYB transcription factor involved in stomatal closure under salt acclimation. Plant Biotechnol J. 2016; 14(6):1345-56.

47. Munns R, Tester M. Mechanisms of salinity tolerance. Annu Rev Plant Biol. 2008:59:651-81.

48. Tenhaken R. Cell wall remodeling under abiotic stress. Front Plant Sci. 2015;5:771.

49. Endler A, Kesten C, Schneider R, Zhang Y, Ivakov A, Froehlich A, Funke N, Persson S. A mechanism for sustained cellulose synthesis during salt stress. Cell. 2015;162(6):1353-64.

50. Moura JCMS, Bonine CAV, de Oliveira Fernandes Viana J, Dornelas MC, Mazzafera P. Abiotic and biotic stresses and changes in the lignin content and composition in plants. J Integr Plant Biol. 2010;52(4):360-76.

51. Kao CH. (66 (2): 87-93) Mechanisms of Salt Tolerance in Rice Plants: Cell Wall-Related Genes and Expansins. J Taiwan Agric Res. 2017;2:87-93.

52. Le Gall H, Philippe F, Domon J-M, Gillet F, Pelloux J, Rayon C. Cell wall metabolism in response to abiotic stress. Plants. 2015;4(1):112-66.

53. Feng W, Kita D, Peaucelle A, Cartwright HN, Doan V, Duan Q, Liu M-C, Maman J, Steinhorst L, Schmitz-Thom I. The FERONIA receptor kinase maintains cell-wall integrity during salt stress through $\mathrm{Ca} 2+$ signaling. Curr Biol. 2018;28(5):666-75 e665

54. Abdelraheem A, Esmaeili N, O'Connell M, Zhang J. Progress and perspective on drought and salt stress tolerance in cotton. Ind Crop Prod. 2019;130: 118-29.

55. Wang $M$, Wang P, Liang F, Ye Z, Li J, Shen C, Pei L, Wang F, Hu J, Tu L. A global survey of alternative splicing in allopolyploid cotton: landscape, complexity and regulation. New Phytol. 2018;217(1):163-78.

56. Cutler SR, Rodriguez PL, Finkelstein RR, Abrams SR. Abscisic acid: emergence of a Core signaling network. Annu Rev Plant Biol. 2010;61(1):651-79.

57. Jiang C, Belfield EJ, Cao Y, Smith JAC, Harberd NP. An Arabidopsis soilsalinity-tolerance mutation confers ethylene-mediated enhancement of sodium/potassium homeostasis. Plant Cell. 2013;25(9):3535-52.

58. Li C-H, Wang G, Zhao J-L, Zhang L-Q, Ai L-F, Han Y-F, Sun D-Y, Zhang S-W, Sun $Y$. The receptor-like kinase SIT1 mediates salt sensitivity by activating MAPK3/6 and regulating ethylene homeostasis in Rice. Plant Cell. 2014;26(6): 2538-53. 
59. Chen D, Ma X, Li C, Zhang W, Xia G, Wang M. A wheat aminocyclopropane1-carboxylate oxidase gene, TaACO1, negatively regulates salinity stress in Arabidopsis thaliana. Plant Cell Rep. 2014;33(11):1815-27.

60. Dong H, Zhen Z, Peng J, Chang L, Gong Q, Wang NN. Loss of ACS7 confers abiotic stress tolerance by modulating ABA sensitivity and accumulation in Arabidopsis. J Exp Bot. 2011;62(14):4875-87.

61. Hassanein RA, EL-Kazzaz AA, Hashem HA, Gabr AM, Ali UI, Hanafy MS, Ebrahim HS. Transformation with the sodium/proton antiporter'AtNHX1'enhances salt tolerance in faba bean ('Vicia faba'L.). Plant Omics. 2019;12(1):48.

62. Palavalasa H, Narasu L, Varshney R, Kavi Kishor P. Genome wide analysis of sodium transporters and expression of $\mathrm{Na}+/ \mathrm{H}+$-antiporter-like protein (SbNHXLP) gene in tomato for salt tolerance; 2017.

63. Pehlivan N, Sun L, Jarrett P, Yang X, Mishra N, Chen L, Kadioglu A, Shen G, Zhang $\mathrm{H}$. Co-overexpressing a plasma membrane and a vacuolar membrane sodium/proton antiporter significantly improves salt tolerance in transgenic Arabidopsis plants. Plant Cell Physiol. 2016;57(5):1069-84.

64. Ji H, Pardo JM, Batelli G, Van Oosten MJ, Bressan RA, Li X. The salt overly sensitive (SOS) pathway: established and emerging roles. Mol Plant. 2013;6(2):275-86.

65. Shen Y, Shen L, Shen Z, Jing W, Ge H, Zhao J, Zhang W. The potassium transporter OsHAK21 functions in the maintenance of ion homeostasis and tolerance to salt stress in rice. Plant Cell Environ. 2015;38(12):2766-79.

66. Yang Y, Guo Y. Elucidating the molecular mechanisms mediating plant saltstress responses. New Phytol. 2017;217(2):523-39.

67. Wang B, Zhai H, He S, Zhang H, Ren Z, Zhang D, Liu Q. A vacuolar $\mathrm{Na}+/ \mathrm{H}+$ antiporter gene, IbNHX2, enhances salt and drought tolerance in transgenic sweetpotato. Sci Hortic. 2016;201:153-66.

68. Wei Y, Xu Y, Lu P, Wang X, Li Z, Cai X, Zhou Z, Wang Y, Zhang Z, Lin Z. Salt stress responsiveness of a wild cotton species (Gossypium klotzschianum) based on transcriptomic analysis. PLoS One. 2017;12(5):e0178313.

69. Yoo M-J, Wendel JF. Comparative evolutionary and developmental dynamics of the cotton (Gossypium hirsutum) fiber transcriptome. PLoS Genet. 2014;10(1):e1004073.

70. Choudhury FK, Rivero RM, Blumwald E, Mittler R. Reactive oxygen species, abiotic stress and stress combination. Plant J. 2017;90(5):856-67.

71. Luo X, Wu J, Li Y, Nan Z, Guo X, Wang Y, Zhang A, Wang Z, Xia G, Tian Y. Synergistic effects of GhSOD1 and GhCAT1 overexpression in cotton chloroplasts on enhancing tolerance to methyl Viologen and salt stresses. PLoS One. 2013;8(1):e54002.

72. Xu R, Yamada M, Fujiyama H. Lipid peroxidation and antioxidative enzymes of two turfgrass species under salinity stress. Pedosphere. 2013;23(2):213-22.

73. Mittler R. Oxidative stress, antioxidants and stress tolerance. Trends Plant Sci. 2002;7(9):405-10

74. Gill SS, Tuteja N. Reactive oxygen species and antioxidant machinery in abiotic stress tolerance in crop plants. Plant Physiol Biochem. 2010;48(12): 909-30.

75. Kurusu T, Kuchitsu K, Tada Y. Plant signaling networks involving Ca2+ and Rboh/Nox-mediated ROS production under salinity stress. Front Plant Sci. 2015;6:427.

76. Zhu D, Hou L, Xiao P, Guo Y, Deyholos MK, Liu X. VVWRKY30, a grape WRKY transcription factor, plays a positive regulatory role under salinity stress. Plant Sci. 2019;280:132-42.

77. Song H, Wang $P$, Hou L, Zhao S, Zhao C, Xia H, Li P, Zhang Y, Bian X, Wang $X$. Global analysis of WRKY genes and their response to dehydration and salt stress in soybean. Front Plant Sci. 2016;7:9.

78. Wang J, Cheng G, Wang C, He Z, Lan X, Zhang S, Lan H. The bHLH transcription factor $\mathrm{CgbHLHOO1}$ is a potential interaction partner of CDPK in halophyte Chenopodium glaucum. Sci Rep. 2017;7(1):8441.

79. Wang F, Zhu H, Chen D, Li Z, Peng R, Yao Q. A grape bHLH transcription factor gene, $\mathrm{VvbHLH1}$, increases the accumulation of flavonoids and enhances salt and drought tolerance in transgenic Arabidopsis thaliana. Plant Cell Tissue Organ Culture (PCTOC). 2016;125(2):387-98.

80. Babitha KC, Vemanna RS, Nataraja KN, Udayakumar M. Overexpression of EcbHLH57 Transcription Factor from Eleusine coracana L. in Tobacco Confers Tolerance to Salt, Oxidative and Drought Stress. PLoS One. 2015;10(9): e0137098

81. Zhai $Y$, Zhang L, Xia C, Fu S, Zhao G, Jia J, Kong X. The wheat transcription factor, TabHLH39, improves tolerance to multiple abiotic stressors in transgenic plants. Biochem Biophys Res Commun. 2016;473(4):1321-7.

82. Deinlein U, Stephan AB, Horie T, Luo W, Xu G, Schroeder J. Plant salttolerance mechanisms. Trends Plant Sci. 2014;19:371-9.
83. Tang X, Liu Y, Wu X, Cheng F, Hu J, Meng X, Ma Z. Response of Antioxidant Enzymes and Digestive Enzymes to Temperature Stress in Lates calcarifer Larvae. Israeli J Aquaculture Bamidgeh. 2018;IJA_70.2018.1537:12.

84. Hu Y, Chen J, Fang L, Zhang Z, Ma W, Niu Y, Ju L, Deng J, Zhao T, Lian J. Gossypium barbadense and Gossypium hirsutum genomes provide insights into the origin and evolution of allotetraploid cotton. Nat Genet. 2019;51(4):739.

85. Wu TD, Watanabe CK. GMAP: a genomic mapping and alignment program for mRNA and EST sequences. Bioinformatics. 2005;21(9):1859-75.

86. Haas BJ, Papanicolaou A, Yassour M, Grabherr M, Blood PD, Bowden J, Couger MB, Eccles D, Li B, Lieber M, MacManes MD, Ott M, Orvis J, Pochet N, Strozzi F, Weeks N, Westerman R, William T, Dewey CN, Henschel R, et al. De novo transcript sequence reconstruction from RNA-seq using the trinity platform for reference generation and analysis. Nat Protoc. 2013;8(8):1494-512.

87. Trapnell C, Roberts A, Goff L, et al. Differential gene and transcript expression analysis of RNA-seq experiments with TopHat and cufflinks. Nat Protoc. 2012; 7(3):562-78.

88. Conesa A, Gotz S, Garcia-Gomez JM, Terol J, Talon M, Robles M. Blast2GO: a universal tool for annotation, visualization and analysis in functional genomics research. Bioinformatics. 2005;21(18):3674-6.

89. Benjamini $Y$, Hochberg Y. Controlling the false discovery rate: a practical and powerful approach to multiple testing. J R Stat Soc Ser B Methodol. 1995:57(1):289-300.

90. Audic S, Claverie JM. The significance of digital gene expression profiles. Genome Res. 1997:7:986-95.

91. Kanehisa M, Araki M, Goto S, Hattori M, Hirakawa M, Itoh M, Katayama T, Kawashima S, Okuda S, Tokimatsu T. KEGG for linking genomes to life and the environment. Nucleic Acids Res. 2007;36:D480-4.

92. Dossa K, Li D, Wang L, Zheng X, Liu A, Yu J, Wei X, Zhou R, Fonceka D, Diouf $D$, Liao $B$, Cissé $N$, Zhang $X$. Transcriptomic, biochemical and physioanatomical investigations shed more light on responses to drought stress in two contrasting sesame genotypes. Sci Rep. 2017;7:8755.

\section{Publisher's Note}

Springer Nature remains neutral with regard to jurisdictional claims in published maps and institutional affiliations.
Ready to submit your research? Choose BMC and benefit from:
- fast, convenient online submission
- thorough peer review by experienced researchers in your field
- rapid publication on acceptance
- support for research data, including large and complex data types
- gold Open Access which fosters wider collaboration and increased citations
- maximum visibility for your research: over $100 \mathrm{M}$ website views per year
At BMC, research is always in progress.
Learn more biomedcentral.com/submissions 